\title{
Noise through Bone Conduction-Differential Diagnosis for the Type of Hearing Loss
}

\author{
Sindhu Parthasarathy ${ }^{1} \odot$, Hemanth N Shetty ${ }^{2}$
}

\begin{abstract}
Aim: The study aims to assess the threshold shift in sensorineural acuity level (SAL) test and bone conduction speech recognition threshold $\left(\mathrm{BC}_{\mathrm{SRT}}\right)$ in mixed and sensorineural hearing loss.

Background: The diagnosis of moderate mixed hearing loss and sensorineural hearing loss is unclear when the air-bone gap (ABG) is at 15 to $20 \mathrm{~dB}$. The study was designed to arrive at the accurate diagnosis of moderate mixed hearing loss and sensorineural hearing loss.

Case description: The study includes five participants diagnosed with bilateral normal hearing $(n=1)$, bilateral conductive hearing loss ( $n=1$ ), bilateral sensorineural hearing loss $(n=1)$, and those with bilateral moderate loss with an ABG of 15 to $20 \mathrm{~dB}(n=2)$. Conventional pure tone audiometry, speech audiometry, immittance, reflexes, and distortion product otoacoustic emission were administered.

Conclusion: The $\mathrm{BC}_{\mathrm{SRT}}$ was almost the same in confirmed normal hearing and conductive hearing loss participants because their $\mathrm{BC}$ sensitivity was within the normal limit. $\mathrm{BC}_{\mathrm{SRT}}$ was high in individuals with sensorineural hearing loss and mixed hearing loss. In addition, the amount of threshold shift in SAL was taken into consideration for the diagnosis.

Clinical significance: The amount of threshold shift in the SAL test with accompanying $\mathrm{BC}_{\mathrm{SRT}}$ concludes that the presence and absence of infection in the middle ear thereby lead to an accurate diagnosis.

Keywords: Bone conduction speech recognition threshold, Mixed hearing loss, Sensorineural acuity level.

Otorhinolaryngology Clinics: An International Journal (2021): 10.5005/jp-journals-10003-1365
\end{abstract}

\section{BACKGROUND}

Many a time diagnoses of moderate mixed hearing loss and sensorineural hearing loss ( $\mathrm{SNHL}$ ) are confusing if a patient's air-bone conduction gap ( $A B G$ ) is at 15-20 dB with A-type tympanogram. The possible reason is the variability of pure tone thresholds which accounts for $5-10 \mathrm{~dB}$. $^{1}$ Most often to lessen confusion, other diagnostic tests such as otoacoustic emission and reflex thresholds are administered. But, these test results may show absence due to hearing loss. Even then confusion is still being present but administering these tests to the test battery merely adds up unnecessary clinical expenses and increases in clinical time. Considering cost and time factors, it is imperative to use a sensorineural acuity test. In the SAL test, narrowband noise is presented through the bone conduction at the forehead. The difference between masked and unmasked thresholds is calculated. The shift in threshold after introducing a noise gives an idea of the origin of the problem in the auditory pathway. It is a well-established fact that bone conduction is a test to assess the acuity of a sensorineural component. Thus, it is assumed that sensorineural acuity level may accurately diagnose patients with having either SNHL or mixed hearing loss, especially for patients who have an ABG of 15-20 with A tympanogram. It is hypothesized that if a patient is suffering from SNHL, then the shift between the unmasked and masked threshold would be less than in a patient suffering from mixed hearing loss. In addition, to validate $S A L$, the bone conduction speech recognition test $\left(B_{S R T}\right)$ was also administered. The following objective is utilized to assess the threshold shift in SAL (at $500 \mathrm{~Hz}, 1$ and $2 \mathrm{kHz}$ ) and $\mathrm{BC}_{\mathrm{SRT}}$ from the participants of the study. \begin{tabular}{l}
\hline \hline 1,2Department of Speech and Hearing, JSS Institute of Speech and \\
Hearing, Mysuru, Karnataka, India \\
Corresponding Author: Sindhu Parthasarathy, Department of Speech \\
and Hearing, JSS Institute of Speech and Hearing, Mysuru, Karnataka, \\
India, Phone: +91 08212548229, e-mail: sindhunp11@gmail.com \\
How to cite this article: Parthasarathy S, Shetty HN. Noise through \\
Bone Conduction-Differential Diagnosis for the Type of Hearing Loss. \\
Int J Otorhinolaryngol Clin 2021;13(1):26-28. \\
Source of support: Nil \\
Conflict of interest: None \\
\hline \hline
\end{tabular}

\section{Case Description}

A total of five participants were involved to determine the threshold shift in $S A L$ and $B C_{S R T}$ from the study participants. Conventional pure tone audiometry, ${ }^{2}$ speech audiometry, ${ }^{3}$ immittance, and reflexes ${ }^{4}$ were administered on these five participants. In addition, if required, distortion product otoacoustic emission (DPOAE) was administered. The results of audiological evaluation revealed that the participants had confirmed bilateral normal hearing sensitivity (hereinafter $A B$ ), bilateral moderate conductive hearing loss (hereinafter $A C$ ), and bilateral moderate sensorineural hearing loss (hereinafter AD) (Fig. 1). However, the other two participants had bilateral moderate loss with $A B G$ of 15 to $20 \mathrm{~dB}$ with A-type tympanogram, absent reflexes, and absent DPOAEs in them. These audiological findings in them were unable to be accurately diagnosed. Thus, SAL and $\mathrm{BC}_{\mathrm{SRT}}$ were performed. The complete audiological profile of all five participants is represented in Table 1. 
Table 1: Audiological findings from participants of the study

\begin{tabular}{|c|c|c|c|c|c|}
\hline Particulars & $A B$ & $A C$ & $A D$ & $A E$ & $A F$ \\
\hline Age (years) & 25 & 40 & 55 & 49 & 53 \\
\hline Complaints & - & $\begin{array}{l}\text { Blocking } \\
\text { sensation }\end{array}$ & $\begin{array}{l}\text { Reduced } \\
\text { hearing }\end{array}$ & $\begin{array}{l}\text { Blocking sensation } \\
\text { and reduced hearing }\end{array}$ & $\begin{array}{l}\text { Unable speech in } \\
\text { noise and reduced } \\
\text { hearing }\end{array}$ \\
\hline PTA (dB HL) & 10 & 55 & 50 & 53.3 & 56.3 \\
\hline $\begin{array}{l}\text { Average } A B G(\mathrm{~dB}) \\
\text { (from } 0.25 \text { to } 2 \mathrm{kHz} \text { ) }\end{array}$ & - & 40 & 5 & 20 & 20 \\
\hline SRT dB & 10 & 45 & 45 & 50 & 45 \\
\hline SIS (\%) & 100 & 100 & 96 & 96 & 96 \\
\hline Tympanogram & A & B & A & A & $A$ \\
\hline Reflexes & $\begin{array}{l}\text { Ipsi- and } \\
\text { contra-present }\end{array}$ & $\begin{array}{l}\text { Ipsi- and } \\
\text { contra-absent }\end{array}$ & $\begin{array}{l}\text { Ipsi- and } \\
\text { contra-elevated }\end{array}$ & $\begin{array}{l}\text { Ipsi-and } \\
\text { contra-absent }\end{array}$ & $\begin{array}{l}\text { Ipsi- and } \\
\text { contra-absent }\end{array}$ \\
\hline DPOAES & Present & Absent & Absent & Absent & Absent \\
\hline $\begin{array}{l}\text { Provisional } \\
\text { diagnosis }\end{array}$ & $\begin{array}{l}\text { Hearing sensitivity } \\
\text { within the normal limit }\end{array}$ & $\begin{array}{l}\text { Conductive } \\
\text { hearing loss }\end{array}$ & SNHL & $? ?$ & $? ?$ \\
\hline
\end{tabular}

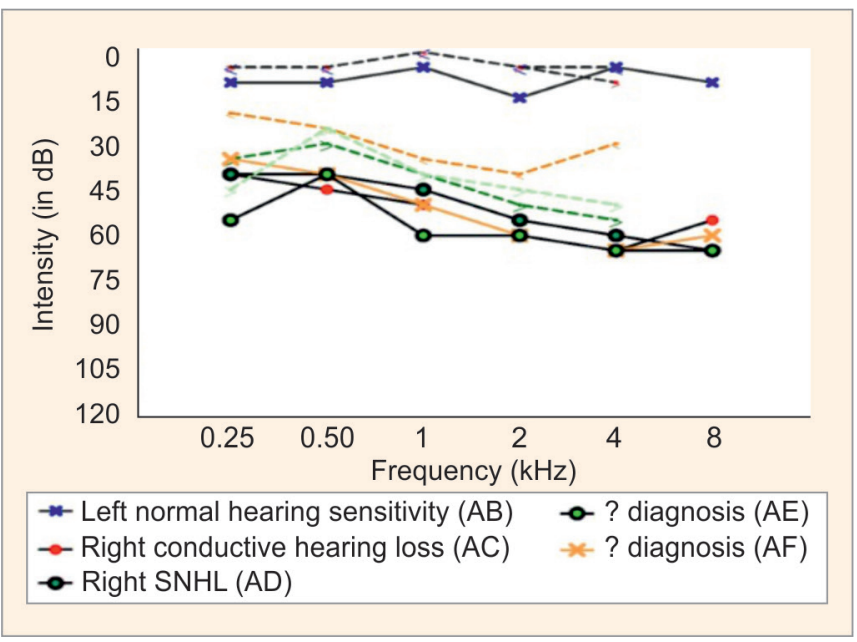

Fig. 1: Hearing thresholds of subjects

\section{Sensorineural Acuity Level Test}

The procedure given by Jerger and Tillman ${ }^{5}$ was adopted to assess the sensorineural acuity level. Initially, air conduction pure tone threshold for frequencies 0.25 to $2 \mathrm{kHz}$ (in octaves) was obtained through bracketing method $(-10$ and $+5 \mathrm{~dB}){ }^{6} \mathrm{~A}$ bone vibrator was positioned at the forehead and a circumaural headphone was placed on each participant's ears. A narrowband masking noise corresponding to a pure tone was delivered through a calibrated bone vibrator at a maximum level of $55 \mathrm{~dB}$. Masked air conduction pure tone threshold for frequencies 0.25 to $2 \mathrm{kHz}$ in octaves was obtained. A threshold shift was calculated by taking the difference between masked and unmasked thresholds (Fig. 2).

\section{$B_{\text {SRT }}$}

The bone vibrator was positioned at the test-ear mastoid. Three spondees were presented at $+12 \mathrm{~dB}$ above the best $\mathrm{BC}$. If two or three spondees were repeated correctly out of three, then the

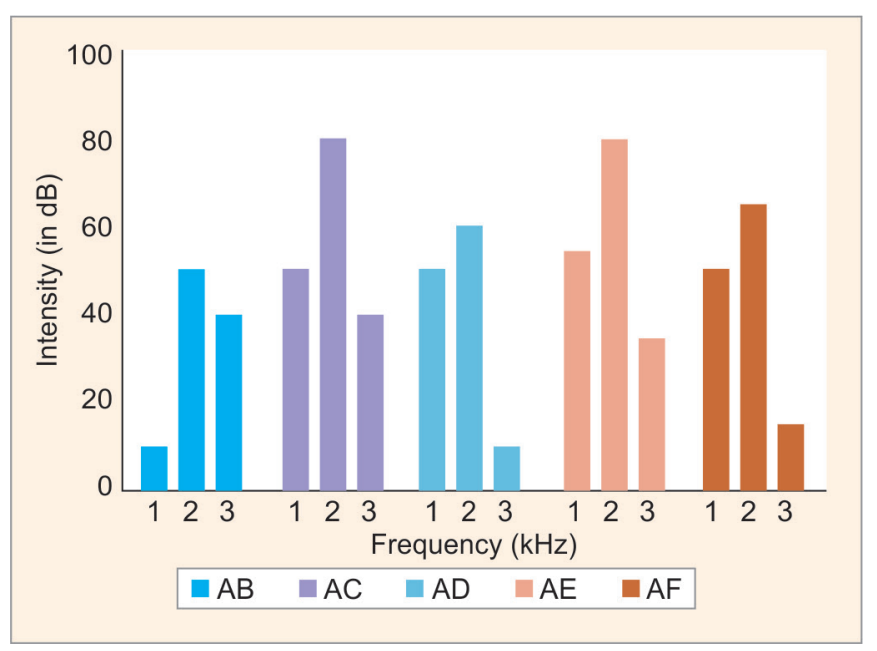

Fig. 2: Results of SAL test

intensity was reduced by $5 \mathrm{~dB}$. If only one spondee or unable to repeat it correctly out of three, then the intensity is increased by $10 \mathrm{~dB}$. With this bracketing method, a low-intensity level at which at least $2 / 3$ responses were obtained was considered as $B C_{S R T}$. To derive genuine $\mathrm{BC}_{\mathrm{SRT}}$ in the target test ear, a masking noise was presented to the contralateral ear through an insert receiver. The level of noise delivered was the $A C$ threshold of the contralateral ear and its ABG (Fig. 3).

\section{Discussion}

The threshold shift in the SAL test for each frequency and $B C_{S R T}$ from study participants was descriptively analyzed. The results of the SAL test for $1 \mathrm{kHz}$ and $\mathrm{BC}_{\mathrm{SRT}}$ from the study participants are depicted in Figure 1. The markings of 1, 2, and 3 in Figure 1 represent an unmasked threshold, masked threshold, and a threshold shift, respectively, for $1 \mathrm{kHz}$ from the SAL test for each participant. 


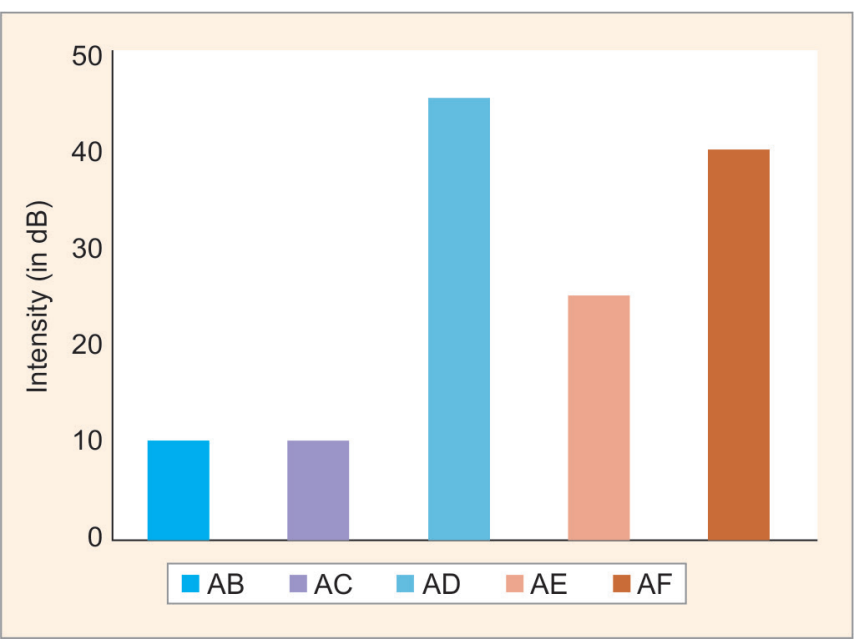

Fig. 3: Results of $B C_{S R T}$

The $\mathrm{BC}_{\mathrm{SRT}}$ was almost the same in confirmed normal hearing $(A B)$ and conductive hearing loss $(A C)$ participants because their $B C$ sensitivity was within the normal limit. However, $B C_{S R T}$ was obtained at $45 \mathrm{~dB}$ in confirmed cases of SNHL (AD). In the case of $\mathrm{SNHL}$, the cochlea is affected and the destiny of the $\mathrm{BC}$ pathway at the peripheral level is the cochlea. In SNHL, the cochlea is damaged; thus, the level required for $B C_{S R T}$ was high. The $B C_{S R T}$ for $A E$ and $A F$ were 25 and $45 \mathrm{~dB}$, respectively. The results $B C_{S R T}$ gives are the notion that in both cases the cochlea is affected but a relatively higher damage might be in the case of $A F$ than $A E$ which was reflected in the $\mathrm{BC}_{\mathrm{SRT}}$ test.

\section{CONCLUSION}

The amount of threshold shift in the SAL test with accompanying $\mathrm{BC}_{\mathrm{SRT}}$ concludes the presence and absence of infection in the middle ear, thereby leading to an accurate diagnosis.

\section{Clinical Significance}

The results of the SAL test on these dilemma cases of the present study throw light on accurate diagnosis. It gives a sign of infection if present in the middle ear to the otolaryngologist for further management.

\section{ACKnowledgment}

The authors extend their sincere gratitude to all the participants of the study.

\section{OrCID}

Sindhu Parthasarathy @ https://orcid.org/0000-0002-9783-986X Hemanth N Shetty (1) https://orcid.org/0000-0002-5161-1368

\section{References}

1. Schmuziger N, Probst R, Smurzynski J. Test-retest reliability of puretone thresholds from 0.5 to $16 \mathrm{kHz}$ using Sennheiser HDA 200 and Etymotic Research ER-2 earphones. Ear Hear 2004;25(2):127-132. DOI: 10.1097/01.aud.0000120361.87401.c8.

2. American Speech-Language-Hearing Association. Guidelines for manual pure- tone threshold audiometry [Guidelines]; 2005. Available from: www.asha.org/policy.

3. American Speech, Language and Hearing. Determining threshold level for speech; 1988. p. 85-89.

4. American Speech-Language-Hearing Association. Guidelines for acoustic immittance screening of middle ear function. Asha 1979;21(288):563-569.

5. Jerger J, Tillman T. A new method for the clinical determination of sensorineural acuity level (SAL). AMA Arch Otolaryngol 1960;71(6):948-955. DOI: 10.1001/archotol.1960.03770060060008.

6. Carhart R, Jerger JF. Preferred method for clinical determination of pure-tone thresholds. J Speech Hear Disord 1959;24(4):330-345. DOI: 10.1044/jshd.2404.330. 